\title{
Education And Economic Growth In Korea, 1966 To 1997
}

Namchul Lee, (E-mail: nclee@krivet.re.kr), Korea Research Institute for Vocational Education and Training

\begin{abstract}
This paper examines the aggregate production function for Korea, using direct estimates of human capital. The contribution of this study possibly provides be affirmation of the myriad role education plays in Korean society, including that of economic growth. I have used the Cobb-Douglas production and time series data of physical capital, labor force, and human capital measurements. In terms of an estimation technique, I have used modern time series methods specifically designed to deal with covariance stationary based on the Augmented Dickey-Fuller $(A D F)$ unit root tests. To date, these techniques have not been frequently used to explore the nature of quantity and quality human capital variables, physical capital, and labor variables. This study has led me to the conclusion that the level of human capital is a significant determinant for economic growth. The coefficient for the quality of human capital stock, however, I found to be negative and significant. These measures ignore the important role of training and learning through practice, and the productivity effect of the educational curriculum.
\end{abstract}

\section{Introduction}

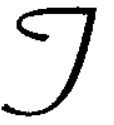

he contribution of education to economic growth can be measured by the use of cross-country studies which emphasize the role of macroeconomic variables as determinants of growth. Such studies have proven to be useful in explaining the correlation between aggregate variables and economic growth. Despite the fact that almost all results obtained through this method of study display a reasonable correlation between a set of macro variables and growth, nearly all of them lack robustness. The main problem in using cross-country studies as a research methodology is the interpretation of the coefficient since it is unreasonable to expect that the coefficient would remain the same for all countries. ${ }^{1}$ As a minimum, the coefficient will be different within specific groups of countries.

Readers with comments or questions are encourages to contact the author via email.
In many research studies, problems related to the measurement of error are extremely important, particularly in studies where the variables are not measured accurately. In particular, cross-country research methodology fails to capture important country-specific characteristics which may be critical to the economy of a specific country. It would therefore seem appropriate that the future direction for further research in this area should be re-directed toward the country-case type of methodology.

Macroeconomists estimate education contribution to growth through the use of aggregate production functions. This economic model explains output as a function of the input of capital and labour. The specifics of the aggregate functions, employing regression techniques, tests the relationship between human capital and economic growth using the Cobb-Douglas production function. The presence of externalities due 
to any one of the inputs, including human capital, should, in principle, be reflected in the estimated coefficient.

The purpose of this paper is to test the aggregate production function for Korea, using direct estimates of human capital. I have used the country-specific time series data on proxy variables. Admittedly, concerns regarding the limitations of a single-country containing only country-specific characteristics are legitimate because such a study may not be representative of a general worldwide development pattern. In terms of an estimation technique, I have used the modern time series methods which are more specifically designed to deal with stationary. To date, these techniques have been little used to explore the nature of the quantity and quality human capital variable, physical capital and labour variables.

\section{Specification of the Econometric Model}

The aggregate production function at the country level is a useful tool ${ }^{2}$ and it is widely used for two principal reasons: First, it is intuitive and simple. Second, there is no alternative treatment of aggregate series that matches its qualities. It is at the dis-aggregated levels, where a great degree of heterogeneity exists among firms, i.e., a sectoral-level or an indus try-level production function. The simple aggregate production function can extended to incorporate human capital. I can consider the continuous and second differentiable production function:

$\mathrm{Y}=\mathrm{A} f(\mathrm{~K}, \mathrm{~L}, \mathrm{H})$

$\mathrm{F}_{\mathrm{K}}>0, \mathrm{~F}_{\mathrm{L}}>0, \mathrm{~F}_{\mathrm{H}}>0, \mathrm{~F}_{\mathrm{KK}}<0, \mathrm{~F}_{\mathrm{LL}}, \mathrm{F}_{H H}<0$,

Estimating the parameters in the CobbDouglas production function with the restriction of linear homogeneity is equivalent to estimate the equations with the ratios of the data. The followings are the model specification. The standard growth accounting methodology with human capital specifies an aggregate production function in which per capita income, $\mathrm{Y}_{\mathrm{t}}$, is de- pendent upon three input factors: basic capital, $\mathrm{K}_{\mathrm{l}}$, labor $\mathrm{L}_{\mathrm{l}}$, human capital, $\mathrm{H}_{\mathrm{l}}$, and the state of technological knowledge as indicated by $\mathrm{A}$, which is assumed to be autonomous, exogenous, and disembodied. Assuming a Cobb-Douglas production function for technology, the growth model in the empirical study is:

$\mathrm{Y}=\mathrm{AK}^{a l}, \mathrm{~L}^{a 2}, \mathrm{H}^{a 3}$,

From a review of literature concerning growth model with human capital, the following equation derive for estimation from the alternative aggregate Cobb--Douglas production. Taking natural logs, I have:

$$
\begin{aligned}
\ln Y_{t}= & \alpha_{0}+\alpha_{1} \ln K+\alpha_{2} L+\varepsilon_{t} \\
\ln Y_{t}= & \alpha_{0}+\alpha_{1} \ln K+\alpha_{2} \ln L+\alpha_{3} \ln H+\varepsilon_{t} \\
\ln Y_{t}= & \alpha_{0}+\alpha_{1} \ln K+\alpha_{2} \ln L+\alpha_{3} \ln P R+\varepsilon_{t} \\
\ln Y_{t}= & \alpha_{0}+\alpha_{1} \ln K+\alpha_{2} \ln L+\alpha_{3} \ln S E+\varepsilon_{t} \\
\ln Y_{t}= & \alpha_{0}+\alpha_{1} \ln K+\alpha_{2} \ln L+\alpha_{3} \ln T+\varepsilon_{t} \\
\ln Y_{t}= & \alpha_{0}+\alpha_{1} \ln K+\alpha_{2} \ln L+\alpha_{3} \ln \mathrm{GB}+\varepsilon_{t} \\
\ln Y_{t}= & \alpha_{0}+\alpha_{1} \ln K+\alpha_{2} \ln L+\alpha_{3} \ln S T+\varepsilon_{t} \\
\ln Y_{t}= & \alpha_{0}+\alpha_{1} \ln K+\alpha_{2} \ln L+\alpha_{3} \ln P R+\alpha_{4} \ln S E \\
& +\alpha_{5} \ln \mathrm{T}+\alpha_{6} \ln \mathrm{GB} \alpha_{7} \ln S T+\varepsilon_{t}
\end{aligned}
$$

Based on Equation, this paper estimates seven logarithm linear functions with the different input variables and same output variables. The dependent variable is GDP in Korean market price by 1990 won. Several independent variables use in the regression equation, the independent variables, physical capital(K), labor(L), and human capital(H). Human capital stock embodies in the labor force was measured by the number of schooling years in the labor force, $\mathrm{H}$. These are measures of educational stock indicated by the number of students in school age in the population who are enrolled at the primary(PR), secondary(SE), and tertiary level(T) of education. In order to analyze the role of human capital accumulation, a number of regression including education enrollment estimate. It means only the quantity of schooling and ignores its quality which is a significant contribution to the process of human capital accumulation. Recently, some researchers ${ }^{3}$ argue that the quality of school is a important 
that the quality of school is a important factor which improves student learning. Equation (4d) and (4e) present quality of human capital inputs such as total government budget to public education budget(GB), and student to teacher ratio(ST). It is no guarantee that a decrease in class size will improve the learning environment within a reasonable range of the median class size. Since this class size is small, reduction in class size may not achieve better student achievement and costly. ${ }^{4}$ Autoregressive technique is used to adjust regression estimates for serial error correlation in time-series data, and the Durbin-Watson statistics is used to test for first-order autocorrelation. The test is based on the residuals from regression analysis, measures the first-order correlation between $\varepsilon_{\mathrm{t}}$ and $\varepsilon_{t+1}$. When this measure of value is close to 2 , the problem of serial correlation is considered not serious. Multicollinearity is a problem in analysis of data where the independent variables are interdependent, hence, influencing on another. To avoid the problem of multicollinearity, and also in order to assess the effects of individual levels of educational stock on economic output, only one educational variable is entered in the equation at a time. Recently Hoxby (1998) obtains that reduction class size from a base of 15 to 30 students have no effect on student achievement. $^{5}$ Finn and Achilles (1990) present a large scale experiment for kindergarten and first grade students in Tennessee. They find that reductions in the class size significantly increase test scores on reading and mathematics examinations. Educational quality is significantly important to the future earnings of students and therefore to allocate efficiency. However, the existing study of the school quality issue restricts to the case of an individual country, a cross comparison of school quality and quantity deserves further attention.

\section{Empirical Results and Remarks}

The results for regressions using the OLS estimation method run on $\log$ GDP are reported in Table 1 and 2. Table 1 displays a number of estimates of the Cobb-Douglas production function. Equation (2) shows the two input cases: the neoclassical production that "economizes" on capital and labor inputs. Equation (4a), (4b), 4c), (4d), and (4e) add the human capital inputs.

Table 1 shows the estimates of the effect quantity of human capital such as primary, secondary, and higher educational enrollment. Equation (3) is the basic production function model, and the coefficients of both capital and labor. Physical capital and labor force variables are positive and statistically significant 1 percent level. Equation (4a) adds primary education which has not a significant positive ( $P R=0.524$ and t-statistics is 1.117) level. Equation (4b) presents that secondary education has a significant effects ( $\mathrm{SE}=0.337$ and the $\mathrm{t}$ statistic $=2.476$ ) at the 5 percent level along with capital and labor inputs. Equation (4c) indicates that higher education is a positive effect $(T=0.336$ and the $t$-statistic $=2.872)$ and significant effects at the 5 percent level.

Seven equation, in terms of the coefficient estimates, evaluates for the physical capital, labor, and human capital variables. The empirical results have vary similar pattern. Physical capital stock always positive and significant at the any meaningful level. Among the human capital variables, primary, secondary, and higher education are always positive effects. The empirical results also show very high explanatory power. The results indicate that human capital in primary, secondary, and higher education contributes relatively 52.4 percent, 33.7 percent, 33.6 percent, respectively, to actual output growth during the 1966-97 for Korea.

According to the World Bank. Policy Research Report (1993), primary education is far the largest contributor to the Korean predicted growth rates of 67 percent because of high primary school enrollment in 1960s. Secondary school enrollment contributes to its growth by 19 percent. Only the quantity of schooling ignores its quality which is a significant contributor to 
Table 1

OLS Results by Using Cobb-Douglas Function

\begin{tabular}{|c|c|c|c|c|}
\hline Variables & $\underline{\mathbf{E q}(3)}$ & $\operatorname{Eg}(4 a)$ & $\operatorname{Eq}(4 b)$ & $\underline{\mathrm{Eq}(4 \mathrm{c})}$ \\
\hline & -0.428 & -9.583 & -3.879 & -5.671 \\
\hline Constant & (3.448) & $(2.643)$ & $(2.834)$ & $(2.785)$ \\
\hline $\begin{array}{l}\text { Capital } \\
\text { (K) }\end{array}$ & $\begin{array}{c}0.497 * * \\
(1.796)\end{array}$ & $\begin{array}{c}0.276 \\
(1.743)\end{array}$ & $\begin{array}{c}0.251^{* *} \\
(1.850)\end{array}$ & $\begin{array}{l}0.243 * \\
(1.751)\end{array}$ \\
\hline $\begin{array}{l}\text { Labor } \\
\text { (L) }\end{array}$ & $\begin{array}{l}1.060^{* * *} \\
(3.787)\end{array}$ & $\begin{array}{c}1.506 \\
(0.401)\end{array}$ & $\begin{array}{c}0.859 \\
(0.447)\end{array}$ & $\begin{array}{c}1.249 \\
(0.445)\end{array}$ \\
\hline $\begin{array}{r}\text { Primary } \\
\text { (PR) }\end{array}$ & . & $\begin{array}{c}0.524 \\
(1.117)\end{array}$ & - & - \\
\hline $\begin{array}{l}\text { Secondary } \\
\text { (SE) }\end{array}$ & - & - & $\begin{array}{l}0.337^{*} \\
(2.476)\end{array}$ & - \\
\hline $\begin{array}{l}\text { Higher } \\
\text { (T) }\end{array}$ & - & - & - & $\begin{array}{l}0.336^{*} \\
(2.872)\end{array}$ \\
\hline SEE & $\begin{array}{l}22.633 \\
(8.726)\end{array}$ & $\begin{array}{l}23.785 \\
(6.330)\end{array}$ & $\begin{array}{l}23.909 \\
(6.449)\end{array}$ & $\begin{array}{l}24.691 \\
(6.892)\end{array}$ \\
\hline $\operatorname{Adj}-R^{2}$ & 0.9689 & 0.9657 & 0.9757 & 0.9432 \\
\hline DW & 1.978 & 1.875 & 1.912 & 1.728 \\
\hline
\end{tabular}

Dependent Variable: $\operatorname{lnGDP}$ in Korea,

Notes: $t$-statistic in parentheses $\left(^{*}\right)$ and $\left({ }^{*}\right)$ denote significance level of 5 percent and 1 percent level, respectively, observation $(\mathrm{N})=32$.

the process of human capital accumulation. It is generally accepted that the quality of schooling has not been improving in the developing countries, despite substantial increases in enrollment ratios in the developing countries. At the initial stages of human capital development, the growth of the quantity of schooling is more relevant policy consideration, whereas schooling becomes more important.

In Table 2, Equations (4d) and (4e) add the quality of school input. There are no reliable aggregate and comprehensive measures for quality of schooling. However, there are several partial indicators of quality of schooling which are included student to teacher ratio, relative teacher salary, teacher career, and total educational expenditure or per capita educational expenditure. Two of them are used in the Table 2 in Equation (4d) and (4e). In Equation (4d), physical capital is positive and statistically sig- nificant at the 1 percent level, but labor force variable is not significant at any meaningful level. Equation (4d) indicators a negative correlation between the growth of public expenditure on education per student during the 1966-97 and significant at the 5 percent level. In Equation (4e), the ST in a negative effect and significant at any meaningful level. In empirical tests, the Durban-Watson statistics reported are after the autoregressive progress(AR) correlation. Because of each the estimated models evidences autorrelated error terms, a two-step CochraneOrcutt estimator employs to improve the efficiency of this estimates. Korean education has expanded enormously in terms of numbers educated person, ${ }^{6}$ but one may doubt whether it has stimulated creativity and instilled morality and civil discipline in the minds of the students. Consequently, other sectors, including public education, limit in the government budget. Korea's new competitive strategy in this age of in- 
Table 2

\section{OLS Estimates of the Cobb-Douglas Function}

\begin{tabular}{lcc} 
Variables & $\underline{\mathrm{Eq}(4 \mathrm{~d})}$ & $\mathrm{Eq}(4 \mathrm{e})$ \\
\hline Constant & -3.779 & -1.572 \\
& $(3.032)$ & $(4.122)$ \\
$\mathrm{K}$ & $0.601^{* *}$ & $0.504^{* *}$ \\
& $1.972)$ & $(1.716)$ \\
$\mathrm{L}$ & 0.895 & 0.903 \\
& $(0.498)$ & $(0.556)$ \\
$\mathrm{GB}$ & $-0.479^{*}$ & - \\
& $(3.161)$ & $-0.498^{*}$ \\
$\mathrm{ST}$ & - & $(2.373)$ \\
& & 25.631 \\
SEE & 25.721 & $(6.408)$ \\
& $(6.430)$ & 0.9472 \\
Adj-R & 0.984 & 3.235 \\
DW & 3.363 &
\end{tabular}

Dependent variable: $\operatorname{lnGDP}$ in Korea,

Notes: $t$-statistic in parentheses $\left(^{*}\right)$ and $\left({ }^{*}\right)$ denote significance level of 5 percent and 1 percent level, respectively, Observation $(N)=32$.

Table 3

Results of Simple Correlation

$\begin{array}{lccc} & \text { LogK } & \underline{\operatorname{LogGDP}} & \underline{\operatorname{LognL}} \\ \log P & 0.5557 & 0.9432 & 0.7246 \\ \text { LogSE } & 0.9749 & 0.9503 & 0.9588 \\ \log T & 0.9651 & 0.9697 & 0.9321\end{array}$

formation and globalization required more active human capital development and a higher quality education. Because adequately supplies the human capital need of a changing industrial structure. Korean education has grown rapidly in terms of quantitative and qualitative aspects. Also, the public education budget has been expanded continuously. Public education budget as percentage of GNP has risen from 2.9 percent in 1970 to 4.4 percent in 1997. However, it is not still high compared with those of industrialized countries. ${ }^{7}$ In this research, education expenditure ratios probably underestimate human capital accumulation.

The high enrollment and the larger size of the primary school in Korea, namely, high rate of student to teacher ratio affect bad education circumstances. ${ }^{8}$ Also Korea's relative allocation to education is smaller than any other advanced countries. Increases in school output will begin to diminish when either the improvement of school input quality, such as lower student to teacher ratio and higher per student educational expenditures a certain level. Human capital theory believes that a fast increase in educational expenditures would bring about great economic growth. However, since the large investment on education does not seem to produce the expected economic growth. Korea has slowed its pace of increasing educational expenditures.

Table 3 and Table 4 indicate that the simple correlation results between human capital inputs 
Table 4

Reports Simple Correlation

$\begin{array}{lcccccc} & \log G D P & \underline{\log K} & \underline{\operatorname{LogL}} & \underline{\log P R} & \underline{\log S E} & \log \mathrm{T} \\ \text { LogGB } & 0.6931 & 0.7568 & 0.7241 & 0.1473 & 0.6341 & 0.7764 \\ \text { LogST } & -0.9204 & -0.9878 & -0.9312 & -0.2143 & -0.8453 & -0.9325\end{array}$

(school enrollment) and physical capital, labor, the rate of growth of GDP. The simple correlation presents that unintuitive findings may be a reflection of a high simple correlation between the human capital and GDP, capital $(\mathrm{K})$, and labor (L).

Primary, secondary, and higher education have a significantly positive effect on economic growth (GDP). All effective labor measures including primary, secondary, and higher educational achievement in the logarithm level specifications have labor share estimates. The labor share estimates vary from 0.7246 for effective labor primary education levels up to 0.9321 for effective labor with higher education. According to human capital theory, all the different streams of human capital stock should contribute positively to the Korean economy. When school enrollments were changed to human capital stock, it is not possible to take into account the different quality and quantity levels of each year of education for different educational cohorts. For different types of education or different educational cohorts, one year of education reflects different amounts of real exposure to knowledge and skills, thus the quality of the educational exposure can differ dramatically. Consequently, failure to include critical information about the quality and quantity of education makes our measure of human capital stock a rough approximation of the actual educational attainment of the labor force.

Table 4 indicates that the simple correlation between the quality of human capital factors (GB and ST) and GDP, capital, labor, and the quantity of human capital inputs such as primary, secondary, and higher education. A notable fea- ture is the negative and significant at the 5 percent level association between InST and other whole factors. Empirical results indicate that there are significant positive relationship between total government budget and total public educational expenditures. Both correlation coefficients exceed 0.6931 . The results show that Korean with high economic productivity spend more on education because economic development (1) demands a more skilled labor force and (2) new technology. Higher levels of education are the means of fulfilling both objectives.

Table 5 summarizes the eight macro variables considered such as GDP, K, L, PR, SE, T, $\mathrm{GB}$, and ST. In addition to this regression, several more regressions run that include time dummy variables to test for any time differences in the Korea. Table 5 presents the OLS results from three different models by using Equation (5). As indicated above, the fully specified model includes three sets of independent variables, a set of predictor variables (i.e., the five human capital stock variables plus labor and physical variables), also a set of time dummy variables. Upon reviewing the three models, in terms of the coefficient estimates, obtain for the human capital and physical capital variables. The basic empirical results exhibit very similar patterns. Physical capital stock is always positive and significant at the 1 percent level.

The coefficient on the labor is a positive effect and insignificant at any meaningful level from the three different periods. The primary education correlates negatively and significant at the 1 percent level with national economic growth the first sub-period, the second period, and the whole period. Secondary education are 
Table 5

Results from the OLS Models

\begin{tabular}{lccc} 
& Whole period & \multicolumn{2}{c}{ Sub-period } \\
\cline { 2 - 3 } Variables & & $1966-80(2)$ & $1981-97(3)$ \\
Constant & $1966-97(1)$ & 11.7043 & 3.1742 \\
& -5.5692 & $(0.0001)$ & $(0.3711)$ \\
K & $(0.1592)$ & $0.2124^{* *}$ & $0.3503^{* *}$ \\
& $0.2251^{*}$ & $(1.9911)$ & $(2.5020)$ \\
L & $(1.8531)$ & 1.8274 & 0.6503 \\
& 1.2860 & $(0.2167)$ & $(0.1635)$ \\
PR & $(0.1207)$ & $-0.2359^{* *}$ & $-0.5061^{* *}$ \\
& $-0.6432^{* *}$ & $(1.8161)$ & $(2.2416)$ \\
SE & $(2.2301)$ & 0.7769 & $0.3680^{*}$ \\
& $0.1137^{*}$ & $(1.1256)$ & $(3.2561)$ \\
H & $(2.5057)$ & 0.7801 & 0.5137 \\
& $0.0224^{* *}$ & $(2.4655)$ & $(2.4783)$ \\
GB & $(3.7111)$ & -0.4519 & $-0.2957^{*}$ \\
& -0.2719 & $(1.0411)$ & $(2.7819)$ \\
ST & $(1.0740)$ & $0.7072^{* *}$ & -0.2134 \\
& -0.9289 & $(1.8428)$ & $(1.2756)$ \\
Adj-R & $(1.0241)$ & 0.9745 & 0.9127 \\
DW & 0.9842 & 2.4490 & 2.3470
\end{tabular}

Dependent variable: lnGDP, 1966-97, 1966-80, and 1981-97, t-statistics in parentheses.

$\left({ }^{*}\right)$ and $\left({ }^{*}\right)$ denote significance level of 5 percent and 1 percent level, respectively.

always positive and significant at the 5 percent level during the whole period and second subperiod. For the different types of human capital stock, higher education makes a positive contribution to economic growth with the whole period and two sub-periods. This stable relationship between national economic growth and human capital, and physical capital variables across all three models indicators some statistical consistency in the results. The GB is negative and statistically insignificant for whole period (1966-97) and the first sub-period (1966-80), while statistically significant at the 5 percent level in the second sub-period (1981-97). This negative effect of the whole period is statistically significant. The negative effect of government education budget to total education expenditure results from small human capital investment. There are a number of potential reasons for the differences between the sub-period and whole-period analysis. ST is negative effect and statistically significant during the whole period and the second sub-period, while statistically significant at the 1 percent level during the first period. By comparing the results obtained from the two sub-period models with the whole period model, some interesting findings emerge. First, there are some consistent findings across the two models. Both the sub-period model and whole-period model indicate that physical capital stock has a positive effect on the national economy. Second, both models suggest that primary and secondary education have positive effect on the economic growth.

In terms of an estimation technique, I have used modern time series methods specifically designed to deal with covariance stationary based on the Augmented Dickey-Fuller (ADF) unit root tests. In modern time series econometrics, the first question of interest in whether or not the time series being considered are stationary. In general, macroeconomics data are not stationary. To test for a unit root in Equation, I used the 
Table 6

Unit Root Test for Physical Capital, Labor, and Human Capital

\begin{tabular}{lrrr} 
ADF & $\underline{\operatorname{LogK}}$ & $\underline{\log L}$ & $\underline{\operatorname{LogH}}$ \\
\hline 0 & -0.3932 & -0.7261 & -1.3761 \\
1 & -2.2153 & -2.4812 & -1.6987
\end{tabular}

procedures developed by Dickey-Fuller (DF) and Augmented Dickey-Fuller (ADF) tests. Table 6 presents unit root test results using the ADF tests with a trend variable for $\ln (\mathrm{K}), \ln (\mathrm{L})$, and $\ln (\mathrm{H})$. The null hypothesis is that the time series are non-stationary.

Now for model $\ln (-y / \Delta L)$, the $1 \%, 5 \%$, and $10 \%$ critical tau statistics as Mackinnon are $-3.5073,-2.8951$, and -2.5844 , respectively. Since the computed tau value is -0.3932 . I did not reject the null hypothesis that the series are non-stationary, i.e., that the series have unit roots. In other words, the $\ln (y / L)$ series in nonstationary. That is, there seems to be no longrun stable relationship between the $y$ and $L$. To allow for the possibility of serial correlation in $\varepsilon_{t}$ I can use a model like Eq. (3) and then apply the ADF test. ${ }^{9}$ Allowing for one lagged value of the first differences of ( $y / L)$, I obtain the following tau value is -0.7261 . It is still below the ADF critical value of $-4.0673(1 \%),-3.4620$ $(5 \%)$, and $-3.1570(10 \%)$, suggesting that the $(y / L)$ time series is not stationary. I conclude that $(y / L)$ data for 1966 to 1997 are nonstationary based on the correlogram and the DF, and ADF unit root tests. The critical tau statistics for each specification are $-4.0673(1 \%)$, $-3.4620(5 \%)$, and $-3.1570(10 \%)$. For each time series $\ln (\mathrm{K})$ and $\ln (\mathrm{H})$, the series exhibits a unit root test. Since the tau statistics is less in absolute terms than the critical tau statistic. Thus, each series is non-stationary.

\section{Summary and Conclusion}

Rather than using cross-country data, annual time-series data, 1966-97, was used for Korea case. The main results obtained from the analysis of the relationship between human capital and economic growth are as follows: (1) Primary, secondary and higher education have had a consistent positive effect upon economic growth during the period 1996-97. The correlation between the dependent variable(GDP) and education enrollment at each level also shows a strong correlation. (2) The use of school enrollment rates as a proxy for human capital investment does not take into account the quality of education provided. In addition to the school enrollment variable, a variable representing the student to teacher ratio and the ratio of the government education budget to total educational expenditure also plays an important role. These adjustments can account for differences in education quality. The Korean educational system attained rapid growth due to the weight of the educational system being concentrated on the quantitative rather than the qualitative side of schooling. These findings suggest that is necessary to formulate more specific conditions under which the economic effects of educational investment can be observed. Next an investigation of whether the pattern of educational investment is significantly altered when controls for linkages to and influences of the world economy and political institutions add to the basic model, also, school enrollment, student to teacher ratio and government budget to educational investment ratio used as proxy measures for human capital accumulation. These measures ignore the important role of training, practical learning, and the effectiveness of the curriculum. The estimates are not sufficient, however, in that they cannot specify the accumulation of human capital through onthe-job training. At the stage of economic development considered here, human capital accum mulation through on-the-job training is critically important and must be taken into account. 


\section{Endnotes}

1. A well-known cross-country study is that of Barro (1991), Kyriacous (1991), Lucas (1993) who employ cross-country data for 98 countries from Summers and Heston (1998) on average school years in the labor force and school enrollment ratios.

2. An outspoken critic of the aggregate production function is N. Kaldo, "Increasing Returns and Technical Progress- A comment on Professor Hick's Articles 13 "Oxford Economic Paper, PP. 1-4, 1961. Wheeler (1980) examines a cross-country data set for 88 poor countries and compares the performance of both the Cobb-Douglas production function and CES production function. He finds that the Cobb-Douglas production function performs no worse than the CES production.

3. Card and Krueger (1992) find that school quality measured by student to teacher ratio,

- term length, and rélative teacher's pay has a significant effect on return to education. The rates of return are systematically higher for individuals who attended schools with lower students-teachers ratio from $30: 1$ to $25: 1$, for example, is associated with a 0.4 percentage point increase in the rate of return to education. Similarly, a 10 percentage point increase in the rate of return to schooling. It is not always true because private schools have different staffing levels, teacher salaries, and students-teachers ratio than public school. Some students with higher socio-economic status attend private schools with a lower ST and higher teacher salaries. This may be only a symbol and /or function of the wealth of the students rather than a solution changing school outcomes, such as increasing test scores or job opportunities. In the United States, the average ST is about 19 for public primary schools and 16 for private primary schools. Bishop (1989) finds that major investments in the quality of schooling (SAT scores) and higher education will improve the quality of the work-force, and thereby increase economic
Volume 16, Number 4

growth.

4. Throsby and Garnicott (1990) show an expensive analysis of the relationship between earnings and school quality for men born in 49 states in the United States between 1920 and 1949. They find that rates of returns are higher for individuals who attended schools with lower ST.

5. Hoxby (1998) use population variation in each grade and school district component to generate instrumental variables for class size and composition.

6. The primary school enrollment was high in 1965 , covering 97.7 percent of all children of school age, and increased to 98.6 percent in 1997, the total age group was in school. The ratio of middle and high school (secondary school) enrollment was 33.9 to 97.8 percent in 1965 and 1997. The tertiary enrollment ratio was 8.8 percent to 68.8 percent in 1965 and 1997. At the tertiary level, the number of students in 1997 is almost thirty times as many as the number in 1966 . The surprisingly high figure for number of students in tertiary institutions was largely due to a reform that raised college enrollment by 30 percent in 1980 .

7. Public expenditure on education as a percentage of GNP is $6.8,7.4,5.9,5.4$; Canada, Denmark, Israel, and France, respectively (UNESCO, statistical Yearbook, 1995).

8. The ratio of student and teacher in Korea in 1995 was the highest in the OECD area for both primary and secondary schools.

9. I estimate the OLS regressions as follow: Dicky-Fuller(DF1); $\left(\_\mathrm{y} / \_\mathrm{L}\right)=R(\mathrm{y} / \mathrm{X})_{\mathrm{t}-1}+\mathrm{x}_{\mathrm{t}}$, $\mathrm{DF}(2) ;(\Delta \mathrm{y} / \Delta \mathrm{X})=B_{1}+R\left(\mathrm{y}_{\mathrm{t}-1} / \mathrm{X}_{\mathrm{t}-1}\right)+\exists t$, firstorder ADF regression (ADF1); $(\wedge y / A X)=$ $R(\mathrm{y} / \mathrm{X})_{\mathrm{t}-1}+\Sigma^{\mathrm{n}} \mathrm{i}=1\left(w_{\mathrm{i}} / \mathrm{X}_{\mathrm{i}-1}\right)+y_{\mathrm{t}}, \quad(\mathrm{ADF} 2)$; (\lrcorner $\mathrm{y} / \triangle \mathrm{X})=B_{1}+R\left(\mathrm{y}_{\mathrm{t}-1} / \mathrm{X}_{\mathrm{t}-1}\right)+\Sigma^{\mathrm{n}} \mathrm{i}=1\left(w_{\mathrm{i}} \mathrm{y}_{\mathrm{t}-1} / \mathrm{X}_{\mathrm{t}-1}\right.$ )$+\exists$ where $X$ is the variable being examined and $t$ is a time trend. In each case the null hypothesis is that $R=0$, that is, there is a unit root. If the error term is autocorrelated, one modifies as follows: $(-\mathrm{y} / \triangle \mathrm{X})=B_{I}$ $+B_{2 \mathrm{t}}+k\left(\mathrm{y}_{\mathrm{t}-1} / \mathrm{X}_{\mathrm{t}-1}\right)+\Sigma^{\mathrm{n}} \mathrm{i}=1 w_{\mathrm{i}}\left(\mathrm{y}_{\mathrm{t}-1} / \mathrm{X}_{\mathrm{t}-1}\right)+{ }_{\mathrm{t}}$ 
Appendix

\section{Data and variables}

1. GDP

I choose to use gross domestic product (GDP) at factor cost as the basic output concept. This concept is more appropriate for the analysis of the productive capacity of the economy than net domestic product. The data are collected from National Accounting Statistics (NAS) reported in National Income Accounts and $\mathrm{Na}$ tional Accounts in Korea and Economic Statistics Yearbook in various issues both of which were published by the Bank of Korea. I use the annual data of real GDP during the 1966-97.

\section{Physical capital (K)}

In other to take an appropriate measure of capital as a factor of production, I need to consider two characteristics of capital: capital stock and capital flow. Theoretically, capital flow rather than capital stock is a more adequate measure of capital input. However, in practice, capital flow measures are not obtainable, for its reason, capital stock uses as capital input in the substitution of capital flow. Physical capital is defined as net non-human capital stocks excluding land inventory stocks. As the measure of capital stock, Pyo's (1992) gross capital stock series is used.

\section{Labor (L)}

Labor is measured as labor hours, which is the product of employment and the average number of the hours worked per year. Variable uses the actual number of people in the labor force, broadly defines as the employed and unemployed who search for a job. This variable is provided by various issues of the ILO's Statistical Yearbook and NSO's Statistical Yearbook (National Statistical Office: NSO) in Korea. Time series data on population exist in the NSO data set for 1966-97 period. This data combines with data on the labor force participation (LFP) rates in Korea from different issues of NSO and from different issues of the World Development Report. These rates refer to the percent people of 15 to 64 years of age who are in the labor force which included employed and activity looking for jobs.

\section{Human capital}

Human capital is measured as the average number of years of education in working age population. The total number of year of education is constructed by applying the perpetual inventory method to the annual number of enrollment students. This analysis is explored the effect of adding human capital accumulation to the Solow model. This study is used measures of the educational enrollment by college educational level of the labor force. $\mathrm{H}$ is human capital stock, educational enrollment level in the labor force. Also, the data for student to teacher ratio (ST) and total government budget to public education budget (GB) come from the table "Educational Level at the First, Second, and Third Level: Institution, Teachers, and Peoples' of UNESCO's Statistical Yearbook (1970-93) "and the KEDI's (Korean Educational Development Institute) Educational Indicators in Korea (195097). Also, data is available in various issues of the World Bank "World Development Report."

\section{References}

1. Bank of Korea. (various years). National Income Accounts in Korea, Seoul, Korea.

2. . (various years), Economic Statistics Yearbook, Seoul, Korea.

3. Barro, R.J. (1991). "Economic Growth in a Cross Section of Countries," Quarterly Journal of Economics, 106, PP. 407-41.

4. Baumol, W.J. (1986). "Productivity Growth Convergence, and Welfare: What the LongRun Show,"

5. American Economic Review, 76(5), PP. 1072-85.

$6 . \quad$, Blackman, S.A.B., and E.N. Wolf. (1989). "Productivity and American Leadership: The Longview, " MIT Press, Massachusetts.

7. Bishop,J. (1989). "Is the Test Score Decline Responsible for the Productivity Growth Decline," American Economic Review, 
79(1), PP. 178-97.

8. Dollar, D. (1991). "Convergence of South Korean on West Germany Level, 1966-78," World Development, 19, PP. 263-74.

9. , and E.N. Wolf. (1993). "Competitiveness Convergence, and International Specialization, MIT Press, Massachusetts.

10. Finn, J.D., and C.M. Achilles. (1990). "Answer and Questions about Class Size: A Statewide Experiment," American Educational Research Journal, 27, PP. 557-77.

11. Hoxby, C. M. (1998). The Effects of Class Size and Composition on Student Achievement: New Evidence from Natural Population Variation, NBER Working Paper, No 6869.

12. International Labor Organization (ILO). (various years). Yearbook of Labor Statistics, Geneva.

13. International Monetary Fund (IMF). (various year). IFS Yearbook, Washington D.C., International Monetary Fund.

14. Kim, Heon-G, and Lee, Nam. C. (1998). "Input-Output Analysis of the Effect on Education and Research on the Korean Economic Structure," Journal of Applied Business Research (Spring), PP. 129-38.

15. Korean Educational Development Institute: (various years). Educational Indicators in Korea, Seoul, Korea.

16. Korean Statistical Association. (1992). Korean Economic Indicators, Seoul, Korea.

17. Kyriacou, G. (1991). Level and Growth Effects of Human Capital, C.V. Starr Center Working Paper No 91-26, New York University.

18. Lee, Nam.C., and A.J. Kondonassis. (1999). "Human Capital and Convergence in Economic Growth in South Korea," Journal of International Economic Studies, Vol 13,
PP. 18-30.

19. Lucas,R.E. (1998). "On the Mechanics of Economic Development," Journal of Monetary Economics, 22, PP. 3-42.

$20 . \quad$ (1993). "Making a Miracle," Econometrica, 61(2), PP. 251-72.

21. Mankiw,F, D. Romer, and D. Weil. (1992). "A Contribution to the Empirics of Economic Growth," Quarterly Journal of Economics, 107, PP. 407-38.

22. Ministry of Labor. (various years). Yearbook of Labor Statistics, Seoul, Korea.

23. Ministry of Education. (various years). Statistical Yearbook of Education, Seoul, Korea.

24. National Statistics Office. (various years). Statistical Indicators in Korea, Seoul, Korea.

25. Pyo, H. (1992). A Synthetic Estimate of the National Wealth of Korea, 1953-90, KDI Working Paper No. 9212, Korea Development Institute, Seoul, Korea.

26. Romer, P.M. (1986). "Increasing Returns and Long-Run Growth," Journal of Political Economy, 94, PP. 1002-37.

27. Solow, R.M. (1956). "A Contribution to the Theory of Economic Growth," Quarterly Journal of Economics, 70, PP. 65-94.

28. . (1957). "Technical Change and the Aggregate Production Function," Review of Economics and Statistics, 39, PP. 312-20.

29. Throsby, C, and K. Gannicott. (1990). "The Quality of Education in the South Pacific," Australia Working Paper No. 90-99.

30. UNESCO. (various years). Statistical Yearbook, Paris, France.

31. World Bank. (various years). World Development Report, Washington, D.C., World Bank. 
Notes 